\title{
Implementing Poetry in the Language Class: A Poetry-Teaching Framework for Prospective English Language Teachers
}

\author{
Safiye İpek Kuru Gönen* \\ Department of English Language Teaching, Anadolu University \\ Corresponding Author: Safiye İpek Kuru Gönen, E-mail: ipekkuru@anadolu.edu.tr
}

\section{ARTICLE INFO}

Article history

Received: April 19, 2018

Accepted: July 27, 2018

Published: October 31, 2018

Volume: 9 Issue: 5

Advance access: August 2018

Conflicts of interest: None

Funding: None

\section{Key words:}

Literature and Language Teaching, Using Poetry in the Language Class, Poetry-teaching Framework, Incorporating Poetry into Language Teaching Methodology,

Pre-service Teacher Reflections

\begin{abstract}
Poetry has often been neglected as a favorable tool for language teaching. What is more, its role to expand human experience and create language awareness has not been fully realized. As a reaction to often-underestimated value of including literature in the language class, this article proposes a poetry-teaching (POT) framework for language practitioners to bridge the gap between literature and language teaching methodology. Step-by-step procedure followed in the framework aimed at helping prospective teachers incorporate poetry into language teaching, while at the same time offering various materials and activities to be used in their future teaching practices. The proposed framework was presented to 21 student teachers at an English Language Teaching (ELT) department of a state university in Turkey to help them integrate the ideas of using poetry in a micro-teaching context. Prospective teachers acted both as learners and teachers while following the steps of the suggested framework, and reflected on this experience through reflective diaries and stimulated recalls of their teaching performances. They also took part in semi-structured interviews at the end of the study. Qualitative analyses revealed that poetry can have a place in language teaching by using a systematic and guided framework tailored to the features of a language classroom. With the help of the proposed framework, implementing poetry in the language class helped to promote motivation, creativity and self-expression along with multi-skill development and interaction among learners. However, incorporating poetry into the language class was challenging in terms of time and effort required and difficulties in material selection and design. This study suggests that poetry can become part of language teacher education. In this regard, this article proposes implications for teachers and teacher educators for the implementation of poetry in language teaching practice.
\end{abstract}

\section{INTRODUCTION}

Literature has long been rejected as a part of language teaching methodology (Carter, 2007) following the fall of Grammar-Translation Method. It is generally viewed as an artistic vein of study that has little or no role in enriching language learning experience. With the rise of the communicative approaches, the dethroned value of literature in the language class has been revised, and how to integrate literature in an L2 class to foster language development has become a recent issue (Bobkina and Dominguez, 2014). Although much emphasis has been directed at the role of literature for language study, there has been no consensus among the practitioners about how to incorporate literature into language teaching (Lima, 2005).

In language teacher education, almost no place is reserved to guide pre-service teachers (PST henceforth) to use literary forms for language teaching purposes. Prospective teachers at many ELT departments are generally required to take various literature related classes, yet they may lack training to use literature for teaching English. They tend to see literature as a way to improve general knowledge putting aside its use while teaching language. Then, how can we overcome such an attitude as teacher trainers and cultivate motivation of using literature in language classes? How can we motivate language learners appreciate literature by educating language teachers before they embark onto their professional life? As a reaction to often underestimated value of including literature, this article proposes a poetry-teaching framework for language practitioners to bridge the gap between literature and language teaching methodology. The aim of this study is to create awareness and motivation for using poetry in the language class by presenting a stepwise framework for prospective language teachers. Based on this purpose, it explores the opinions of PSTs about the use of the proposed framework and integration of poetry into English language teaching. The findings of the study may illuminate further attempts of incorporating poetry into language teaching practice.

\section{REVIEW OF LITERATURE}

Using poems in the language classroom have many reported benefits from both linguistic and literary perspectives. Nu- 
merous linguistic gains can be counted such as poems' potential to enrich vocabulary (Lazar, 1996), improve pronunciation, foster grammatical knowledge (K1rkgöz, 2008), and practice language skills and forms (Tomlinson, 1986) along with its value in providing a rich source for language input (Duff and Maley, 2007). Poetry also promotes literary appreciation by increasing cross-cultural awareness (Lazar, 1996), improving expressive abilities (Iida, 2016) and constructing social connections among students (Chanmann-Taylor, Bleyle, Hwang and Zhang, 2016). Using poems enhances more personal involvement in the language class to find a ground for expressing personal ideas within a larger human reality (Hess, 2003). As a result, poetry reading is assumed to have a facilitative effect on promoting linguistic and cultural knowledge (Hanauer, 2001).

Despite these advantages, using poetry in the language class is somewhat marginalized by many teachers. Poetic language involves manipulation of grammar and lexis to suit for orthographical and phonological congruence; and thus, deviation from standard norms of language may be considered inaccessible to foreign language learners. Teachers' reluctance towards using poems may stem from considerations about following textbook materials which reserve little or no room for literary texts, and lack of time and motivation to include poetry and literature in general (McIlroy, 2013). As a result, potential of using poetry to foster language development has not been realized so far.

\section{Approaches and Models in Teaching Poetry in the Language Class}

While analyzing and teaching poetry, or any piece of literature, teachers may base their practices in different theoretical lenses such as new criticism, structuralism, stylistic approach and reader-response approach. The first two approaches almost have no place for the reader, or historical/ social context of literary texts. New criticism purports importance to a literary text with an objective stance, and structuralism highlights mechanical-almost scientific-analysis in literary reading (Carter and Long, 1991). However, reader's (that is the learner's) personal involvement, enhancement of cultural awareness and development of language skills are basic considerations for many teachers while using literary texts in the language classroom. Hence, these approaches are not referred to while creating the proposed framework here as they may fall short behind in invoking an interest of learners in a foreign language classroom. The latter two theoretical approaches, on the other hand, offer practical applications in foreign language teaching since they value the reader and his/her experiences with the language of the text for meaning making. One of them is the stylistic approach directed at analyzing formal features of a poem at various linguistic levels including vocabulary, grammar, discourse and phonology (Short, 1996). This approach fits within the purposes of language instruction in many L2 contexts to teach formal aspects of the English language and create language awareness (Akyel, 1995; Rosenkjar, 2006; Watson and Zyngier, 2007). That is, learners may focus their attention on formation of linguistic structures in poems to create an effect, and analysis of word choice to express different feelings and ideas. In this way, it is possible for learners to gain an awareness on how language is formed and discourse is created in the contexts of poems.

Another approach is the reader response approach rooted in transactional theory. Accordingly, reciprocal relationship between the reader and the poem is important in interpreting meaning rather than seeking for a fixed, single interpretation (Hirvela, 1996). This approach proposes that it is the individual learner who extracts meaning from a poem through a personal transaction with the text via dynamic process of experience and exploration. According to Rosenblatt (1994), these transactions can range from an efferent stance of reading for information to an aesthetic stance of reading for pleasure or experience. In a foreign language class, adopting such an approach may help learners interpret texts by building up personal relations with the texts, and by sharing related ideas and feelings. Transactions with the text may include reading poems to gather information through comprehension based activities, and building relations between the poem and the students' lives through various speaking, writing or drama activities. Such a stance may help learners get the pleasure of reading and share their personal experiences.

Apart from the aforementioned approaches for poetry teaching, there are three models practitioners can resort to while using poetry in a language class; namely, language, cultural and personal growth models (Carter and Long, 1991). Language model is directed at deconstructing literary texts into their linguistic forms without a literary goal by putting emphasis on designing and using language-based activities. Cultural model pays attention to transmission of cultural aspects of a language community evident in literary texts whereas personal growth model highlights interaction between the reader and the literary text. In this way, personal growth model regards the text as a way to generate feelings and ideas on the basis of readers' own experiences.

With respect to approaches and models that have been presented so far, it is clear that they propose different perspectives by either prioritizing personal appreciation or linguistic gains. Widdowson (1992) emphasizes mutual benefits of literary interpretation based on personal understanding and linguistic analysis. Bridging the gap between poetry as a literary genre and language teaching methodology in this paper compromises to melt these two perspectives in the same pot rather than seeing them as opposed to each other. A balance is required to match both linguistic and responsive needs of the learners. Moreover, there has been an increasing agreement on the insufficiency of dependence on one single approach or model, and thus; there is a tendency on the integration of different approaches and models based on the needs of the language learners for the effective implementation of literature into language practice (Divsar and Tahriri, 2009; Savvidou, 2004; Van, 2009; Timucin, 2001). As a result, while composing the proposed framework here, aforementioned approaches and models are considered as tools to be used in different parts of the lesson to foster motivation, personal appreciation and linguistic awareness. 


\section{PoetryTeaching (POT) Framework}

POT framework was designed to enhance the idea of implementing poetry in language teaching. This framework targeted at combining both stylistic and reader response approaches by building relationship between readers and poems as well as by making use of various linguistic choices poems provide for teaching purposes. What is more, POT framework integrates ideas from all three models proposed by Carter and Long (1991) seeing them as complementary to each other while using poetry in language teaching. POT is also nourished by the idea of meaningful literacy practice proposed by Hanauer (2012) which prioritizes reflection on life experiences through literary texts. Specific attention has also been given to foster all four strands of language (reading, listening, speaking and writing) as much as possible to highlight the role of poetry to achieve linguistic outcomes. In each step of the framework, specific features of poetry (i.e. economic use of language, deviant forms used, figures of speech, inherent meanings in lines etc.) were given attention to make this framework peculiar to using poetry in the language classroom. Table 1 below shows the steps of the framework along with a range of possible activities that can be used with any poem.

As it is visible in Table 1, the first four steps can be used to present various activities and ideas related to using poetry. Here, practitioners are in the role of language learners. These four steps are also useful for teachers who would like to use poems in their classes. Although participants in this study had advanced level of L2 proficiency and used rather complex poems, this framework is also suitable for using simple poems with lower level learners in a language class. The last two steps are intended to help prospective teachers use ideas in the first four steps to incorporate poetry into language teaching. This time, they are in the role of teachers. Steps 5 and 6 then are exclusively beneficial for teacher training purposes. POT is designed for prospective teachers to train them on how to use poetry in a language class by following the six-step procedure. They can follow a similar procedure in their future practices while working with language learners. All in all, with the help of this stepwise framework, PSTs are transformed from learners into teachers by taking active roles in each step.

\section{Aim and Significance of the Study}

Success of language learning and literary understanding largely depends on teacher's scaffolding. Teachers can appreciate the use of literary texts for language teaching when training opportunities are provided (Dymoke \& Hughes, 2009; Paran, 2008). Hughes and Dymoke (2011) report feelings of anxiety on the part of the teachers while using poetry in their classes, and urge training pre-service teachers on how to teach poetry for transformation of hesitation into motivation. This article proposes a framework with the aim of incorporating poetry in language teacher education, and it explores how prospective teachers perceive the use of such framework for language teaching purposes.

Guiding PSTs see poems as valuable resources to be used while teaching language, and helping them reflect on such experience lay at the heart of the framework. Steps of the proposed framework may include practices familiar to foreign language teachers in different contexts. What is original about this framework is that it is specifically designed for incorporating poetry, rather than literature in general. Moreover, it offers a comprehensive and systematic guide both for teacher trainers and teachers alike to follow with various alternative practices while using poetry in a language class. The main aim here is to foster motivation for using poetry in the language classroom. In this study, the proposed framework helps PSTs integrate the ideas of using poetry in a micro-teaching context. The following research questions are asked to explore the effectiveness of the framework as a tool for teacher education:

- What are the opinions... of PSTs about POT framework designed for integrating poetry into language teaching?

- How do PSTs reflect on using poetry for teaching purposes based on their actual micro-teaching performances?

\section{METHOD}

\section{Participants and the Context}

21 PSTs in the ELT department of a Turkish university participated in the study. Participants were selected based on the ideas of convenient sampling (Creswell, 2005) as they were available and voluntary. PSTs in this study were enrolled in an elective poetry class. All of them were third year students who were supposed to become English language teachers upon their graduation the following year. Participants were expected to perform advanced level of mastery in English language since their academic studies centered on using all four skills successfully in various courses. In the previous literature classes they had taken, PSTs analyzed poems mainly by focusing on literary devices and main themes. All PSTs were taking methodology classes related to ELT concurrently, in which they learnt how to take students' attention, tailor activities according to students' needs, prepare lesson plans and teach language skills. Hence, PSTs were familiar with lesson planning and material design. However, literature and language teaching methodology were mainly regarded in isolation from each other. That is, PSTs received no training in using literature for language teaching purposes.

At the beginning of the term, PSTs were informed about the outcomes of the poetry class they were enrolled in. Accordingly, this class aimed at helping them get into the atmosphere of the poems and the era, discuss the feelings evoked, work on different linguistic choices in poems, and design various activities and materials to create an awareness on how poetry could be used in EFL/ESL classes. PSTs signed consent forms before the class since all their efforts depended on their voluntary participation.

\section{Implementation of the POT Framework}

PSTs were trained in the use of POT framework by following the procedures given below:

- Presentation of POT: The instructor of the course (that is the researcher) introduced the POT framework and presented all steps with examples. The rationale behind each step and how they served for various outcomes regarding linguistic, cultural understanding and 
Table 1. Steps and possible activities for the POT framework

\begin{tabular}{ll}
\hline Steps & \\
\hline 1 & Tune-in: The aim of this step is to activate schema to lead learners \\
into the poem and give them necessary background information. \\
To do this, various visual and auditory materials can be used to \\
create a relaxing atmosphere. A familiar key concept or topic \\
relevant to the poem can activate learners' prior experiences. \\
From a stylistic perspective, vocabulary and grammar points can \\
also be highlighted by giving striking stanzas from the poem.
\end{tabular}

\section{Possible activities}

- Elicit main concept/theme through brainstorming or by designing a semantic map with key words

- Present necessary background information related to the poet or the period via various sources (flashcards, slides, animations, online channels)

- Talk about an anecdote or use background music that can be associated with the mood of the poem

- Teach difficult key words and concepts important for understanding the poem

- Design jigsaw activity by giving each student a stanza within small groups

- Start with the linguistic analysis of a striking line/stanza

- Present or revise a grammar point evident in the poem by paying attention to how it is used in the poem

- Talk about how linguistic forms are presented within lines by extracting samples from the poem

2 Basic Comprehension: In this step, students' understanding overall meaning of the poem is important. Poems evoke feelings within the limits of stanzas; hence guiding learners identify the main idea is crucial. Various comprehension activities to get the gist of the poem can be designed. To ease basic comprehension, glossaries with key vocabulary can be given along with the poems.

3 Detailed Analysis: In this step, further questions for detailed understanding can be asked along with various activities for literary appreciation/interpretation and linguistic analysis. Moreover, details in the poem that may help to understand the social and cultural factors/values can be analyzed.

4 Cultivation: This is a kind of personalization step aimed at cultivating information from the poem into learners' own lives. At this point, they are familiar with the poem. Hence, they can be involved in various speaking, listening, writing or even drama activities (in pairs/groups) to foster interaction and linguistic practice. Linking poetry with popular culture may help to cultivate further interest in the poem.

5 Bridge: This step targets at building a bridge between the poem and language teaching methodology. This step serves as an opportunity for training practitioners (PSTs) on how to use poems in micro teaching contexts. In the previous steps, they are in the role of the students participating in the activities. Thus, they form ideas about what types of activities are boring or motivating while using poems. This step is where they can value the importance of teacher's scaffolding to promote motivation.
- Ask comprehension questions in different formats (e.g multiple choice, yes/no, wh-) or fill in the table/chart for the gist

- Read aloud when appropriate to ease basic comprehension

- Talk about what the poet tries to tell and how s/he tells it in a limited space via lines

- Focus on linguistic choices such as tense or adjective use, and how they are formulated in the poem (i.e. how inversion is used and what effect it creates)

- Find what referring expressions mean

- Identify figures of speech and rhyme

- Talk about poet's choice of words and replace them with different words to identify the effect created by word selection

- Analyze cultural/social factors underlying meaning

- Put together jumbled lines

- Work on synonyms/antonyms of selected words

- Translate poems into other mediums such as prose or drama.

- Change the speaker, addressee, mood, tone or some linguistic aspects

- Write/add another stanza

- Dramatize the poem with background music and costumes, or design a role play activity

- Read the poem with different types of music in the background and discuss their appropriateness

- Read aloud the poem with different modes of feelings (i.e. angry, content, frustrated, depressed etc.) and discuss the feelings evoked in each mode of reading

- Make a short movie, a T.V show or a radio broadcast based on the poem. Create characters and work on dubbing

- Write scenarios in small groups or pairs

- Create a piece of art about the poem

- Discuss how ideas in the poem are reflected/changed in popular culture through remixing popular songs with poems

- Create a sort of microteaching context and ask practitioners prepare a short lesson plan to use the poem in the class.

- Guide practitioners formulate learning outcomes (for personal growth, cultural understanding or linguistic gains) - Motivate practitioners to use various activities given in the previous steps 
Table 1. Continued

\begin{tabular}{lll}
\hline Steps & Possible activities \\
\hline 6 & Reflection: In this step, it is important to find out how practitioners & - Use written reflections such as reflective diaries/journals \\
benefit from incorporating poetry into language teaching, and & and checklists \\
whether efforts to bridge the gap between literature and language & - Implement collaborative and/or dialogic reflection tools \\
teaching are useful in practice. Guiding practitioners reflect on & such as ad-hoc self-observation frameworks and stimulated \\
their experiences through various tools may help to create an & recalls based on video recordings of teaching performances \\
awareness on using poems in language practice. & \\
\hline
\end{tabular}

personal growth gains were clarified.

- PSTs as learners: PSTs studied various poems for three weeks (three hours a week) by using the first four steps (Tune-in, Basic Comprehension, Detailed Analysis and Cultivation) in the framework. PSTs were informed that they would focus on various poems in the following weeks within these four-step procedure and their attention was drawn into how the instructor moved from one step into another. Famous poems from different eras were selected without any simplification since the participants in this study had a high level of proficiency. Where necessary, glossaries with unfamiliar words or concepts were provided. At this phase, they were language learners. Instructor designed activities and materials appropriate for the first four steps while working on the selected poems. The aim here was to familiarize PSTs with the idea of using poetry for cultivating personal growth, fostering cultural understanding and creating linguistic awareness. In this way, PSTs were able to see how poems could be used in a language class. At the end of each class, the instructor led discussions on how they felt about using poems this way.

- PSTs as teachers: It was time for PSTs to be in the role of teachers, and the Step 5 (Bridge) of POT served for this aim. PSTs designed lessons for using poems within a micro-teaching context. They were asked to present their lesson plans to their classmates by regarding them as language learners. Participants were formed into groups of three and each group was responsible for selecting a poem for their classmates and plan a lesson with various activities and materials. PSTs were guided to use the first four steps in their planning. All participants were familiar with the steps and further support was provided for any difficulty they experienced while planning. They were free to choose poems that would be interesting for their classmates. Micro-teaching experiences lasted for seven weeks. While planning the lesson, they were instructed to pay attention to the following:

- Write outcomes for your lesson with respect to linguistic gains, cultural understanding and personal experiences

- Use the four-step procedure for using the poem you selected. Design activities and materials appropriate for using your poem in the language class by paying attention to rationale of each step.

- While choosing activities and materials, make sure they involve all learners (your classmates) in your lesson and motivate them as much as possible.

- Reflecting on experience: Step 6 (Reflection) aimed at guiding PSTs reflect on their experience with POT framework. They wrote reflective diaries for seven times after each presentation of poems by their classmates. Moreover, each group recorded their own teaching experiences for further reflection in stimulated recalls.

\section{Instruments}

In order to explore PSTs' opinions about POT framework, they wrote reflective diaries upon each implementation of poetry for teaching purposes. Participants wrote a total of seven reflective diaries. These diaries were used to gather data regarding their thoughts and feelings for using poems in the language class. Reflective diary/journal is a valuable tool in teacher education to elicit teachers' perceptions and feelings about an application or their own experiences (Gallego, 2014). Hence, it appeared as an appropriate instrument for the purposes of the study.

Walsh and Mann (2015) call for a data-led approach to reflection featuring spoken reflective processes in order to provide vivid and detailed reflections. Thus, not only diaries but also stimulated recall reflections were collected to see how PSTs perceived using POT and using poetry in general in a language class. Those stimulated recalls have potential to raise awareness about specific features of teaching practices based on actual evidences (Lyle, 2003). To guide those reflections, some guided questions were asked to lead STs while writing diaries and reflecting on actual performances (see Appendix A). Another reflection tool was the focus-group interviews conducted at the end of the study (see Appendix B) to shed further light on incorporating poetry into the language class. In this way, data were triangulated to see the effectiveness of the proposed framework.

\section{Data Collection and Analysis}

The study lasted for a total of 10 weeks. In the first three weeks, POT framework was presented to the participants by regarding them as language learners. The following seven weeks were reserved for micro-teaching experiences of PSTs acting as language teachers by using the framework. Reflective diaries after each micro-teaching experience were collected from all participants. Each group video recorded their teaching experiences and reflected on these recordings by watching them afterwards. At the end of the study, focus-group interviews were conducted with each group of participants. Interviews were transcribed verbatim for qualitative analysis.

As for the data analysis, a total of seven reflective diaries for each PST and focus-group interviews were analyzed 
qualitatively based on the ideas of grounded theory (Miles and Huberman, 1994). In order to explore PSTs' perceptions, Constant Comparison Method (CCM) appeared as an appropriate method here as it targeted at revealing emerging themes out of the data rather than preconceived categories (Boeije, 2002; Leong, Joseph and Boulay, 2010). Accordingly, communication units in which participants expressed their opinions on the use of POT and their experiences regarding the use of poetry for language study were identified. In this study, a communication unit referred to a single idea, opinion or feeling participants expressed about the implementation of the POT framework. Identified communication units were constantly compared and contrasted by following the ideas of CCM until similar communication units were grouped to reach sub-categories. A similar constant comparison methodology was used to form main categories out of similar sub-categories. As a result, all categories and sub-categories identified were generated from the data. Two separate raters analyzed the data by coding, sorting and identifying categories to reach at a consensus. Although researcher was one of the raters in the analysis process, specific attention was given to analyze the anonymous data from an objective lens within the methodology of CCM. Both raters were experienced in the analysis method. Inter-rater reliability was calculated by following the formula (the number of agreements/the number of agreements $(x)$ the number of disagreements multiplied by 100) suggested by Tawney and Gast (1984). Inter-reliability was.92, which indicated a high rate of reliability.

\section{RESULTS AND DISCUSSION}

\section{Reflections on the POT Framework}

The first research question explored the opinions of PSTs about the POT framework. As a result of qualitative analysis via CCM, a total of 436 communication units were identified from reflective diaries, stimulated recall reflections and focused-group interviews. These communication units were formed under eleven sub-categories and three main categories. Table 2 below shows main and sub-categories related to PSTs' opinions on using POT. Sample statements were extracted from PSTs' reflections on the implementation of the POT framework.

According to Table 2, PSTs mostly favored the framework as it created awareness on the role of poetry in a language class and on language practice. That is, POT promoted motivation for reading and appreciating poetry. One of the participants (PST14) stated in a sample statement that even with long poems including many unknown words, they were able to realize the potential of poetry to evoke feelings and add emotion to language. POT was also found to foster creativity since lots of different and creative ideas were used in the class in various steps of the framework. For example, for some poems they created a piece of art (i.e. creating their own piece of art in a group work based on the descriptions in the poem) or changed the medium of the poem (i.e., writing a short story by changing the lines into prose and discussing the effect of such change). Moreover, as expressed by one of the participants (PST9) in a sample statement, with the

Table 2. Main and sub-categories related to PST's opinions on the POT Framework

\begin{tabular}{|c|c|c|}
\hline & $\mathbf{N *}$ & Sample Statements \\
\hline Awareness on the role of poetry & & \multirow{4}{*}{$\begin{array}{l}\text { "Today I really feel motivated. This poem is very long and full of new words. } \\
\text { I thought it would be a boring class. Instead, it was very enjoyable with the help of } \\
\text { music, videos and colorful pens. With the activities we used, I see now how poetry } \\
\text { adds emotion to language." (PST14-reflective diary) }\end{array}$} \\
\hline POT promotes... & & \\
\hline motivation & 102 & \\
\hline creativity & 72 & \\
\hline self-expression & 53 & \multirow{4}{*}{$\begin{array}{l}\text { "What we did in today's class changed my ideas. I did not think I could express } \\
\text { myself while discussing a poem in this way. Now, it is not difficult. I have lots of } \\
\text { things to say once I am into the poem." (PST9 reflective diary) }\end{array}$} \\
\hline real-life connections & 28 & \\
\hline understanding of human nature & 11 & \\
\hline Total & 266 & \\
\hline Awareness on language practice & & \multirow{3}{*}{$\begin{array}{l}\text { "We talked a lot, wrote short stories, listened to music, drew pictures, lots of } \\
\text { different activities. We did all those in English. I learned many new words and } \\
\text { expressions." (PST2 interview) }\end{array}$} \\
\hline POT promotes... & & \\
\hline multi-skill development & 73 & \\
\hline interaction in the class & 34 & \multirow{3}{*}{$\begin{array}{l}\text { "All the activities used in this poetry class involved us in the lesson. We discussed } \\
\text { together and played with the language. We can use poetry to teach any language } \\
\text { skill in a meaningful way." (PST7 interview) }\end{array}$} \\
\hline context for teaching & 24 & \\
\hline Total & 131 & \\
\hline \multicolumn{3}{|l|}{ Challenges } \\
\hline POT is challenging in terms of... & & \multirow{6}{*}{$\begin{array}{l}\text { "Using poems in the class take time. There are almost no prepared materials, the } \\
\text { teacher has to prepare everything. I think it is difficult to include poetry in the class } \\
\text { within the tight schedules of teachers." (PST18 interview) }\end{array}$} \\
\hline time and effort & 18 & \\
\hline material selection/design & 12 & \\
\hline linguistic outcomes & 9 & \\
\hline Total & 39 & \\
\hline Main total & 436 & \\
\hline
\end{tabular}

$\mathrm{N}^{*}$ : Number of communication units 
help of the activities and step-by step procedure, participants found a ground to express themselves and discuss their ideas and feelings with their peers. They were also able to make connections between the poems and themselves by considering the ideas and feelings they experienced in their daily lives. While following the steps of POT, participants realized that a poem that was written a long time ago by somebody else in a different part of the world could reflect similar feelings based on similar human experiences. Hence, from a reader response perspective, the participants were able to make connections between themselves and the poems by sharing their real-life experiences and responding to the poems in a creative way.

The POT framework also created awareness on developing language skills. While implementing the steps of the framework, PSTs were involved in various activities which required them to read, listen to, write and speak in the target language. As expressed by one of the participants (PST2), it promoted multi-skill development and resulted in learning new words and expressions. Within the stylistic perspective, participants analyzed the poems at linguistic levels and gained awareness on the potential of using poetry for language practice. What is more, the participants interacted with each other through discussions and sharing of personal interpretations. They were involved in group activities; and thus, had a ground for communicating with each other. PSTs also realized the effectiveness of POT to create a context for teaching. Using poems within a step-by-step procedure provided a natural context to present language in a meaningful way. PSTs were in the role of learners during the first four steps, and then were in the role of teachers in the last two steps. They had a chance to see the effectiveness of the framework for teaching purposes. It was visible from their reflections that they appreciated the potential of using this framework for language teaching purposes.

Although qualitative analyses revealed favorable results for the POT framework, PSTs also expressed some challenges they faced. As it can be seen in the table above, PST18 complained about lack of finding prepared materials for using poems in the classroom. That is, practitioners had to spend time and effort to prepare their own materials for each poem, which brought forward further challenges in the tight schedule of teachers. Since poems provoked motivation in the classroom and were useful for promoting creativity in general, PSTs expressed some concerns for finding specific linguistic outcomes for each poem they were using. Poems were not written for pedagogic purposes to teach linguistic features; hence, practitioners had to spend more effort in identifying appropriate outcomes for linguistic study. However, the difficulties PSTs mentioned were a few compared to positive views related to the POT framework. As a result, PSTs' opinions on the POT framework revealed a positive tendency for implementing poetry in the language classroom. Their stimulated recall reflections on micro-teaching experiences, in which they acted as teachers, also supported this finding. The following sub-section presents a sample stimulated recall reflection on using poetry for language teaching.

\section{Reflections on micro-teaching experiences- a sample}

PSTs tried ideas presented through POT in the first four steps while they were in the role of learners. In the final two steps of POT, they were in the role of teachers to incorporate poetry into a language class. In this regard, PSTs were able to have a broad understanding about how learners were drawn into poems, and how poems served to meet both linguistic and responsive needs of the learners. In addition to reflections on POT, prospective teachers in the study also reflected on their actual teaching performances of using poetry in a language class based on video recordings. In Step 5, Bridge, PSTs collaboratively worked to design an activity based on the poem analyzed. They chose one group member as the teacher for the actual performance and video recorded these performances. In Step 6, they reflected on this performance as a group by watching these recordings. These simulated recall reflections were taken for further analysis. Table 3 below includes a sample of these dialogical reflections about an activity PSTs prepared and used in the class.

In the sample extract and reflection in Table 3, it was apparent that the activity created an unexpected effect. The learners were cultivated into the poem they analyzed in the previous steps and responded personally. They reflected their own stories on the 'urns' they created, and their peers interpreted these stories from their own perspectives. Such an activity helped all learners make a connection between the poem and their own lives, and transformed the urn from an object in the poem into a means to foster personal reflection. In this way, participants learned personal details about each other; and thus, the poem became a tool to cater mutual understanding. While reflecting on their teaching performance, PSTs 4-5 and 6 realized how their activity in the classroom helped to elicit some personal responses to build up a sharing atmosphere. Dialogical reflection revealed that PSTs gained an awareness on the potential of using poetry to promote personal understanding. PSTs who were in the role of teachers in this activity did not expect to see such an effect, and they were fond of creating such an atmosphere in the classroom. A poem they used in the class helped them to reveal individual stories which otherwise would not be elicited. Since poems reflect deeper human experiences embedded with emotions and opinions, realizing the effectiveness of using them as tools for individual contribution unlocked personal experiences. As a result, reflections on the activity above underlined that poems could be used to create personal and collaborative meaning in the language classroom. The findings of the study in general yielded that when prospective teachers were provided with pedagogical tools such as the framework presented here, they would be able to gain awareness on the role of poetry in the language class.

\section{Discussion}

PSTs in this study generally perceived the POT framework favorably benefiting much from it to gain awareness on the role of poetry for language practice. With the help of POT, they were motivated to use poetry in the language class. It was evident from the results that the proposed framework 
Table 3. Sample dialogical reflection on an activity

\begin{tabular}{|c|c|}
\hline Extract & Reflection \\
\hline $\begin{array}{l}\text { T: OK. Time is up. Now I will collect your own descriptions of } \\
\text { your own urn and distribute it randomly(.) You will receive the urn } \\
\text { of any of your friends. I will give you two minutes to look what } \\
\text { is on that urn and comment on it (.), what it looks like and what } \\
\text { memory it talks about (.) Then the owner of that urn will tell the } \\
\text { real story behind it. } \\
\text {-After two minutes- } \\
\text { T: who wants to comment? Any volunteer? -pointing to a } \\
\text { learner-yes...you can start...oh please show the urn you have } \\
\text {-learner shows the urn to whole class- } \\
\text { L: Hmm...this ( } 2 \text { sec) I think it is about dancing...two people are } \\
\text { dancing (.) one man and a woman. It can be tango or salsa...look } \\
\text { at the skirt of the woman. I can see the audience. And on the corner } \\
\text { is a kind of.trophy. I think they won a kind of...competition. } \\
\text { T: Whose urn is it? } \\
\text {-one of the students raise his hand- O.K is it true? I mean what } \\
\text { your friend said } \\
\text { L2: Yeah...It was the time I and my dancing partner won a } \\
\text { competition. } \\
\text {-learners show a reaction of surprise- } \\
\text { L3: Vaoww... are you dancing? } \\
\text { L2: yes... for years } \\
\text { L4: I didn't know that } \\
\text { T: Teacher } \\
\text { L: Learner }\end{array}$ & $\begin{array}{l}\text { PSTs 4-5 and } 6 \text { are reflecting on the activity by watching the } \\
\text { recording of the particular extract on the left. } \\
\text { PST4: -she was the teacher- I didn't expect this activity to turn } \\
\text { into such thing...I mean they were all involved and shared their } \\
\text { ideas... willingly. } \\
\text { PST5: (everybody) learned many things about each other...look. } \\
\text { how they are ( } 2 \text { sec) } \\
\text { PST6: (surprised?) } \\
\text { PST5: Yes. Surprised! } \\
\text { PST6: I can't believe he is dancing } \\
\text {-laughter- } \\
\text { PST3: I didn't know that...I can't imagine him dancing like a } \\
\text { pro } \\
\text {-laughter- } \\
\text { PST5: we all have different lives and we don't know so much } \\
\text { about it } \\
\text { PST3: (we have no idea) } \\
\text { PST6: maybe we can watch him dancing one day } \\
\text { PST5: yeah why not? -laughter- } \\
\text { PST3: I didn't assume this activity would have an effect like this } \\
\text { PST 3: yes.me too } \\
\text { PST6: (another surprise) } \\
\text { Key for transcription } \\
\text { (sec): time elapses } \\
\text { (.): instant pauses } \\
\text {... : on-going talk } \\
\text {-text-: explanations } \\
\text { (text): overlapping talk }\end{array}$ \\
\hline
\end{tabular}

Activity: Depicting an unforgettable memory. The reflection was on a groups' activity they prepared for step 4-Cultivation. The activity was about the poem 'Ode on a Grecian Urn' by J. Keats. PST distributed a picture of an urn with a blank space, and instructed the learners to fill in this space with the description of a memory they couldn't forget. They could write or draw anything that reflect an unforgettable memory on the urn. On the left part is the extract from the part of the lesson where the teacher is checking learners' responses, and on the right part is the PSTs' dialogical reflections.

guided them to understand human nature and comment on it in a creative fashion. In this respect, active participation in exploring both linguistic and cultural processes resulted in self-discovery through access to others' experiences (Carter, 2007). Some other positive perceptions centered on realizing the potential of using poetry in the language class to foster multi-skill development, and to create more communication opportunities with peers. Incorporating poetry was perceived as beneficial for fostering language skills, interaction, and creating context for teaching in the language class. This finding is aligned with previous research on the benefits of using poetry for language development (Hanauer, 2001; Kırkgöz, 2008; Lazar, 1996; Tomlinson, 1986). Furthermore, when they were in the role of learners, PSTs worked in a collaborative fashion through discussion and sharing of ideas despite the fact that poetry has often been considered as an individual activity. Kim (2004) highlights such opportunity poetry brings in the language classroom stating that it increases interaction with reference to responsiveness, emotional engagement and authenticity. Creating an interactive atmosphere is crucial to engage learners in literary experiences in a foreign language classroom (Al-Mahrooqi, 2012). The findings of the study revealed that when poetry is effectively incorporated into the language classroom in an interactive fashion, it may promote expressive abilities of the learners (Iida, 2016), and serve as a common ground to construct social connections within the class environment (Chanmann-Taylor et al., 2016). In this sense, POT utilizes interaction among PSTs featuring their reserves for interpretation, discussion and mutual understanding. As evident in reflections, PSTs had a chance to practice language and had fun especially while creating something of their own. Hence, it was implied that poetry could become a vehicle for genuine creation in the language classroom as well.

As visible in PSTs' reflections, their perceptions were generally positive albeit a few concerns about including poetry into tight curriculum. Teachers may be unwilling to use literature due to some negative beliefs and preconceptions and these may affect the way they approach literary texts for language practice (Hughes and Dymoke, 2011). As echoed previously by McIlroy (2013), PSTs in this study perceived poetry integration challenging in terms of time and effort required and difficulties in material selection and design. Since poetry is not considered as a tool for language teaching in general, teachers may need to resort to their own resources for selecting poems for language practice and preparing materials and activities. Although PSTs tackled with certain challenges while implementing poetry in the language study, 
they experienced poetry in a different and enjoyable sense both in the role of learners and teachers. Hence, some of them were able to change their negative beliefs about using literature in the language classroom. One reason of this outcome would be related to the potential of POT to influence classroom atmosphere positively by giving PSTs various opportunities to create, involve, enjoy and reflect. As a result, incorporating poetry into language learning is likely to support whole person learning from a holistic perspective by taking affective factors into account (Paran, 2008). It was visible in the reflections that PSTs were able to experience poetry in a different sense compared to their previous experiences with literature. With the help of POT, they enjoyed reading and dealing with poetry, and built up connections with poems and real life. They gained an understanding about their own feelings with respect to the ones presented in poems. This finding underlines poetry's potential to build up connections with learners' own lives (Baron, 2013) and to create a positive attitude towards using literature in language study. Once the prospective teachers enjoyed reading poetry, they appreciated implementing poetry into language study when they were in the role of teachers. If we want to cultivate appreciation of poetry and literature in general in the language class, the first step would be to create opportunities for first hand experiences. Then, they may have a chance to enhance the idea of incorporating poetry into language teaching.

Qualitative analyses yielded that activities based on the poems helped PSTs get to know each other better and learn some personal information. In this way, building up relationships based on reciprocal exchange of ideas might likely to strengthen personal and social connections. Mittal (2016) emphasizes such promoting effect of poetry to build communication and enhance emotions in a peer group. The reflective attitude of PSTs towards the interactive outcomes of using poetry helped to unveil the valuable effect of using poems as a way to develop mutual understanding. Hence, the dialogical reflections of the PSTs underlined the power of using poetry in the language classroom for revealing emotions, unlocking personal reactions and shaping language learning into a more personal experience. As it was evident in a sample reflection on micro-teaching experience, through personal exploration and meaning-making process, poetry can foster more personal involvement in the language class (Hess, 2003), and strengthen social bonds among learners (Chanmann-Taylor et al., 2016).

Training prospective teachers on how to respond to literary texts can help to create a common ground for sharing experiences. In this vein, POT followed the implications of the reader-response approach by prioritizing the experience with the text as the cradle for interaction and active-meaning making (Lynn, 2008). For PST education, providing an active, analytic and reflective reading experience for prospective teachers is also important to be able to guide them in their future practices (Garzon and Castaneda-Pena, 2015). In alignment with the positive outcomes of the study for incorporating poetry into language practice, a meaningful literacy practice experience based on reflection and personalization (Hanauer, 2012) can be promoted in foreign language teacher education. Encouraging teacher candidates to respond per- sonally to literary texts may also benefit their own students in their future classroom contexts (McIntosh, 2010). When PSTs practice such experience as exemplified in the extract above, it can undeniably guide their future attempts of using poetry in a language class. Prospective teachers who are aware that poetry can serve as a valuable tool for expression and personal interpretation may encourage a similar attitude among learners when they become professionals.

As a result, by using POT to incorporate poetry into the language class, PSTs realized the potential of sharing experiences for better interaction, cooperation and understanding. It echoes the idea that when poems are used to create interactive and collaborative atmosphere, they promote communication and individual expression as well (Finch, 2003). It can be assumed from PSTs' reflections that receiving training on using poetry broadened their horizons and paved the way for more motivation, language development, and learner involvement. The following extract shows how experience related to POT created awareness about using poetry in language teaching:

"I think I discovered myself both as a learner and as a teacher. I understand that a piece of poem can create a sense of togetherness in the class while at the same time encourage individuals to express themselves confidently. I believe my students in the future will enjoy reading poems when I use the techniques I learned here." (PST12-interview)

\section{CONCLUSIONS}

This study aimed to propose a poetry-teaching framework (POT) for prospective English language teachers, and to offer training on using poetry for language teaching. For this purpose, PSTs were engaged in incorporation of poetry into language practice, first as learners and then as teachers. While they were in the role of learners in the first four steps of the suggested framework, they had a chance to take part in activities designed to integrate poetry for language practice. In the last two steps, they were in the role of teachers and used poems for teaching purposes in a micro-teaching context. As a result, they experienced how poetry could be used as a tool to foster language development at different phases of an English lesson. PSTs reflected on these first-hand experiences of incorporating poetry into language practice by following a stepwise framework. Both written and stimulated recall reflections revealed that PSTs benefited much from this dual experience and had the opportunity to gain awareness on how poetry could be integrated into language teaching. Exploration of PSTs' perceptions have highlighted the importance of offering guided training in language teacher education for the effective implementation of literature into language teaching agenda (Al-Mahrooqui, 2012; Iskhak, 2015; Paran, 2008).

It is evident that poetry can become part of language teaching methodology. With the help of POT, PSTs had a chance to feel the transformation from students to teachers. When poetry becomes accessible to teacher candidates, they may feel more motivated to use poems while teaching a foreign language. Lack of training on using literature as part of language teaching methodology creates a tendency to underestimate 
the role of poetry in EFL/ESL teaching contexts (Çetinavcı and Tütüniş, 2012). Creating a positive poetry experience in PST education and providing opportunities may help to change negative beliefs about the role of poetry in language teaching (Hughes and Dymoke, 2011). In this study, PSTs stated that experiencing poetry through POT helped them to change their negative beliefs into positive, and to gain awareness about integrating poetry in language teaching. It was clear from the PSTs' reflections that poetry could be used as a resource for thought-provoking discussions and language awareness. This study was limited as the participants only used advanced level of long and complicated poems due to their high proficiency level. However, PSTs' reflections on various poems pinpointed that even long stretches of, and relatively difficult literary texts, could also be used in a language class. In this regard, when they become professionals they can use similar shorter and easier texts with their students in the language class. When the steps of the proposed framework is analyzed, it becomes clear that various ideas and outcomes related to the steps of the framework can be adapted for using any type and level of poems in the language classroom.

Bobkina and Dominguez (2014) highlight the importance of research evidence to offer ways to integrate literature in a language classroom. How to use literature for language teaching purposes and how to train teachers on the effective implementation of literary texts are still questions unanswered. In this respect, this article provides insight into the use of poetry as a tool to train prospective language teachers. More research is undeniably required to investigate the effectiveness of similar models or frameworks to foster the incorporation of literature into language teaching curricula. Research reported here was limited in terms of its dependence on the reflections of PSTs in the study. Thus, investigating whether PSTs would use the ideas presented through POT in their future teaching practices might provide deeper insight about the effectiveness of the framework.

\section{REFERENCES}

Al-Mahrooqui, R. (2012). "An investigation of literature teaching methodologies at a higher educational institution in Oman", TESOL Journal, 6, pp. 172-180.

Akyel, A. (1995). "Stylistic analysis of poetry: A perspective from an initial training course in TEFL", TESL Canada Journal,13(1), pp. 63-73.

Baron,L. (2013). "Close reading and personal connection: The power of poetry", Educator's Voice, VI, pp. 48-53.

Bobkina, J. and Dominguez, E. (2014). "The use of literature and literary texts in the EFL classroom; between consensus and controversy," International Journal of Applied Linguistics and English Literature, 3(2), pp. 248-260.

Boeije, H. 2002. "A purposeful approach to the Constant Comparison Method in the analysis of qualitative interviews." Quality \& Quantity, 36, 391-409.

Carter, R. and Long, M.N. (1991). Teaching Literature, Longman, Harlow.

Carter,R. (2007). "Literature and language teaching 19862006: a review", International Journal of Applied Linguistics, 17(1), pp. 3-13.
Çetinavcı, U. R., and Tütüniș, B. (2012). "Making use of poems to teach English", The Journal of Language Teaching and Learning, Vol. 2 No. 2, pp. 75-88.

Chanmann-Taylor,M., Bleyle, S., Hwang,Y., and Zhang, K. (2016). "Teaching poetry in TESOL teacher education: heightened attention to language as well as to cultural and political critique through poetry writing", TESOL Journal, doi:10.1002/tesj.263.

Divsar, H. and Tahriri, A. (2009). "Investigating the effectiveness of an integrated approach to teaching literature in an EFL context", Pan-Pacific Association of Applied Linguistics, Vol.2 No. 13, pp.105-116.

Duff,A. and Maley, A. (2007). Literature (Second Edition), Oxford University Press, Oxford.

Dymoke, S. and Hughes, J. (2009). "Using a poetry wiki: How can the medium support pre-service teachers of English in their professional learning about writing poetry and teaching poetry in a digital age?", English Teaching: Practice and Critique, Vol.8 No.3, pp.91-106.

Finch, A. (2003). "Using poems to teach English", English Language Teaching, Vol. 15 No. 2, pp.29-45.

Gallego, M. 2014. "Professional development of graduate teaching assistants in faculty-like positions: Fostering reflective practices through reflective teaching journals." Journal of the Scholarship of Teaching and Learning 14(2), 96-110.

Garzon,E. and Castaneda-Pena,H. (2015). "Applying the reader-response theory to literary texts in EFL-preservice teachers' initial education", English Language Teaching, 8(8), pp. 187-198.

Hanauer, D.I. (2001). "Focus-on-cultural understanding: Literary reading in the second language classroom", CAUCE, Revista de Filologia y su Didactica, 24, pp. 389-404.

Hanauer,D.I. (2012). "Meaningful literacy: writing poetry in the language classroom", Language Teaching, 45(1), pp.105-115.

Hess, N. (2003). "Real language through poetry: a formula for meaning making”, ELT Journal, 57(1), pp. 19-25.

Hirvela, A. (1996). "Reader-response theory and ELT", ELT Journal, 50(2), pp. 127-134.

Hirvela, A. (2001). "Connecting reading and writing through literature", in D. Belcher and A. Hirvela (Eds.), Linking Literacies: Perspectives in L2 Reading-Writing Connections, The University of Michican Press, Ann Arbor, MI, pp. 109-134.

Hughes,J. and Dymoke, S. (2011). "Wiki-Ed poetry: Transforming pre-service teachers' preconceptions about poetry and poetry teaching", Journal of Adolescent \& Adult Literacy, 55(1), pp. 46-56.

Iida, A. (2016). "Poetic identity in second language writing: exploring an EFL learner's study abroad experience", Eurasian Journal of Applied Linguistics, 2(1), pp. 1-14.

Iskhak. (2015). "The application of reader-response theory in enhancing student teachers' affective and linguistic growth: A classroom action research in EFL teacher education in Indonesia", The English Teacher, Vol. XLIV No.2, pp. 43-55.

Kırkgöz, Y. (2008). "Using poetry as a model for creating English poems", Journal of Language and Linguistic Studies, 4(2), pp. 94-106. 
Kim, M. (2004). "Literature discussions in adult L2 learning", Language and Education,18(2), pp. 145-166.

Lazar, G. (1996). "Literature and language teaching; exploring literary texts with the language learner", TESOL Quarterly, 30(4,) 773-776.

Leong, P., S. R. H. Joseph, and R. Boulay. 2010. “Applying constant comparative and discourse analyses to virtual worlds research." Journal of Virtual Worlds Research,3(1), 3-26.

Lima, C. (2005). "Is the rest silence...?", IATEFL Voices, Issue 186, pp.4-5.

Lyle, J. (2003). "Stimulated recall: A report on its use in naturalistic research", British Educational Research Journal, Vol. 29 No.6, pp. 861-878.

Lynn, S. (2008). Texts and contexts: Writing about literature with critical theory $\left(5^{\text {th }} E d\right.$.), Pearson Education Inc, New York.

McIlroy, T. (2013). "What teachers talk about when talk about poetry: discussing literary texts in the university EFL context", The Journal of Literature in Language Teaching, 2(1), pp. 26-31.

McIntosh, J.E. (2010). "Reader response journal: Novice teachers reflect on their implementation process", Journal of Language and Literacy Education, Vol. 6 No.1, pp. 119-133.

Miles, M. B., and Huberman, A. M. (1994). Qualitative Data Analysis: An Expanded Sourcebook, Sage Publications, London.

Mittal,R. (2016). "Poetry is language at its most distilled and powerful: bringing poetry in language classes can make language understanding and communication skills better", Linguistics and Literature Studies, 4(1), pp. 52-56.

Paran, A. (2008). "The role of literature in instructed foreign language learning and teaching: an evidence-based survey", Language Teaching, 41(4), pp. 465-496.
Rosenkjar, P. (2006). "Learning and teaching how a poem means: Literary stylistics for EFL undergraduates and language teachers in Japan", in A. Paran and J. Burton (Eds.), Literature in Language Teaching and Learning, TESOL, Alexandria VA, pp. 117-131.

Rosenblatt, L. M. (1994). The Reader, the Text, the Poem: The Transactional Theory of the Literary Work. Southern Illinois University Press, United States of America.

Savvidou, C. (2004). "An integrated approach to the teaching of literature in the EFL classroom", The Internet TESL Journal, available at http://iteslj.org/Techniques/Savvidou-Literature.html (accessed 15 December 2016).

Short, M. (1996). Exploring the Language of Poetry, Plays and Prose, Longman, Harlow.

Timucin, M. (2001). "Gaining insight into alternative teaching approaches employed in an EFL literature class", CAUCE, Revista de Filologia y su Didactica, 24, pp. 269-293.

Tomlinson, B. (1986). "Using poetry with mixed ability language classes", ELT Journal, 40(1), pp. 33-41.

Van, T. (2009). "The relevance of literary analysis to teaching literature in the EFL classroom", English Teaching Forum, Vol. 47 No.3, pp.2-9.

Walsh, S., and Mann, S. (2015). "Doing reflective practice: a data-led way forward”. ELT Journal, ccv018.

Watson,G and Zyngier, S. (Eds.). (2007). Literature and Stylistics for Language Learners: Theory and Practice, Basingstoke, Macmillan/Palgrave.

Widdowson, H. G. (1992). "The significance of poetry", in Practical Stylistics: An approach to Poetry, Oxford University Press, New York, pp. 3-73.

\section{APPENDIX A. GUIDING REFLECTION QUESTIONS}

\section{Diaries}

- What do you think about the role of poetry in language teaching?

- What do you think about preparing language teaching materials based on poems?

- What do you think about the framework (what we do in this class) for implementing poetry in ELT?

\section{Video recordings}

When you watch your poetry teaching performance ...

- how do you feel about using poems as part of teaching practice?

- what do you think about your own performance of teaching poetry?

\section{APPENDIX B. FOCUS-GROUP INTERVIEW QUESTIONS}

1. What do you think about the poetry-teaching framework implemented in this class throughout the term?

2. Is there any difference between previous literature classes and this one? If yes, briefly talk about it.

3. Is there any change in your views about using poems as language teaching materials before and after this class? 
